\title{
Growth of long term survivors of liver transplantation
}

\author{
R M Viner, J T M Forton, T J Cole, I H Clark, G Noble-Jamieson, N D Barnes
}

\begin{abstract}
Objective-To assess growth in survivors of liver transplantation.

Study design-Growth was studied in 105 children up to seven years after liver transplantation.

Results-At transplantation, mean height standard deviation score $(\mathrm{zH})$ was -1.22 but $19 \%$ of patients were severely growth retarded (height below 0.4 th centile). Growth and pubertal retardation were seen in the first six months after liver transplantation. Significant catch up in growth and puberty continued for more than five years. At five years, mean $\mathrm{zH}$ was -0.95 and at seven years -0.84 . The mean $\mathrm{zH}$ of patients at final height was $-0.55 . \mathrm{zH}$ at six months was predicted by $\mathrm{zH}$ and bilirubin at the time of transplantation and prednisolone dose at six months. At four years, $\mathrm{zH}$ was predicted by $\mathrm{zH}$ at the time of transplantation and the cumulative prednisolone dose. There was no association between $\mathrm{zH}$ and age at transplantation, sex, or diagnosis, although those with biliary atresia and those undergoing transplantation under 2 years of age showed more initial growth delay and subsequent catch up. Average age at menarche was 14.2 years.
\end{abstract}

Conclusions-The mean height of the group to have reached final height after liver transplantation was on the 27 th centile. Those transplanted earlier in childhood are likely to achieve more normal final heights. High steroid dose, poor liver function, and retransplantation are associated with poorer height outcomes. Persisting severe short stature is largely confined to children with severely retarded growth at the time of transplantation. Transient delay in puberty and menarche occur early after transplantation, although appropriate pubertal progress is resumed after two to three years.

(Arch Dis Child 1999;80:235-240)

Keywords: growth; liver transplantation; long term survivors; puberty

MRC-Dunn Nutrition Unit, Cambridge, UK T J Cole

Correspondence to: Dr R M Viner, Director of Adolescent Medicine, Middlesex Hospital,

Mortimer Street, London W1N 8AA, UK.

email: R.Viner@ich.ucl.ac.uk

Accepted 9 July 1998 present, few data are available on growth in long term survivors of transplantation. Most children who undergo transplantation already treatment for children is now the accepted ease. It is hoped that successful transplantation will result not only in long term survival but also in normal growth and development. At have moderate to severe growth failure. ${ }^{1-3}$ Further growth retardation is commonly seen in the first six months after transplantation but catch up growth often occurs from six to 24 months. ${ }^{45}$ To date, few studies have assessed growth more than two years after transplantation. Codoner-Franch et al found that mean height standard deviation scores (zH scores) in 119 children increased from -1.30 at liver transplantation to -0.99 at four years $(n=26)$, indicating a mean improvement of approximately half a centile channel. ${ }^{6}$ Rodeck et al found that the greatest height velocity during catch up growth was at two years, falling again in the third and fourth years. ${ }^{7}$ Most recently, Holt et al reported that mean height standard deviation score remained around -1.0 at five years after transplantation, although numbers at five years were small. ${ }^{8}$ No data exist on height outcomes beyond five years after transplantation.

Factors that may affect growth after transplantation include previous growth failure, feeding problems, transplantation complications and impairment of liver function, ${ }^{4} 578$ delayed development, ${ }^{9}$ renal impairment, ${ }^{3}$ and immunosuppression. ${ }^{10-13}$ High doses of glucocorticoids are a major factor responsible for poor linear growth in the first six months, ${ }^{6}{ }^{9}$ and if it is necessary to continue with high doses, such doses also affect growth during the second and subsequent years. ${ }^{467}$ Concerns about growth suppression and increasing confidence in other agents have resulted in many clinicians reducing steroid doses, using alternate day regimens, and stopping steroids three to six months after transplantation. ${ }^{9}$ Cyclosporin has not been associated with poor growth. ${ }^{4}$ The primary diagnosis may be relevant, because rapid catch up has been reported in metabolic disorders, biliary atresia, antitrypsin deficiency, and cryptogenic cirrhosis, but not in Alagille syndrome or familial cirrhosis. $^{5614}$

There is also a lack of data on skeletal maturity and endocrine function. Growth potential as assessed by delay in bone age was reported to improve after liver transplantation. ${ }^{15}$ Studies of nocturnal growth hormone $(\mathrm{GH})$ secretion showed a reduced mean area under the curve and low mean $\mathrm{GH}$ peak concentrations at 12 months, with low basal cortisol concentrations and blunted cortisol responses to adrenocorticotrophic hormone (ACTH) and hypoglycaemic stimulation. ${ }^{415} \quad$ Corticosteroid stimulated somatostatin secretion might be the main cause of the suppression of growth hormone secretion. ${ }^{16}$ The relevance of impaired 
Table 1 Age, sex, and diagnosis of patients undergoing liver transplantation $(n=105)$

\begin{tabular}{lc}
\hline Sex & \\
Male & $53(50.5)$ \\
Female & $52(49.5)$ \\
Age at transplantation & \\
$<2$ years & $24(22.9)$ \\
$2-5$ years & $28(26.6)$ \\
$>5$ years & $53(50.5)$ \\
Diagnosis & \\
Biliary atresia & $59(56.2)$ \\
Antitrypsin deficiency & $13(12.4)$ \\
Familial and cryptogenic cirrhosis & $8(7.6)$ \\
Cystic fibrosis & $5(4.8)$ \\
Tyrosinaemia & $5(4.8)$ \\
Chronic hepatitis & $4(3.8)$ \\
Oxalosis & $4(3.8)$ \\
Familial hypercholesterolaemia & $3(2.9)$ \\
Non-syndromic biliary hypoplasia & $1(0.9)$ \\
Criglar-Najiar syndrome & $1(0.9)$ \\
Fulminant hepatic failure & $1(0.9)$ \\
Idiopathic sclerosing cholangitis & $1(0.9)$ \\
\end{tabular}

Values are n (\%).

production of liver derived growth factors is being investigated. ${ }^{17}$

No data are available on the relation of long term growth and final height to parental heights, or on pubertal development in adolescents. The 12 year experience of the Addenbrooke's children's liver transplantation programme offered an opportunity to reassess long term growth taking these factors into account.

\section{Methods}

Data were collected retrospectively from the records of children who survived more than 12 months after orthotopic liver transplantation in Cambridge between August 1984 and August 1994. One year survival was $85 \%$, and five year survival was $72 \%$. Data were available for 105 patients. Three children with Alagille syndrome were excluded because they showed the growth failure associated with this condition. ${ }^{14}$ Table 1 summarises the clinical details of the patients. Anthropometric measurements described as taken at the time of liver transplantation were obtained in the two month period before the procedure. During the period of our study a triple immunosuppression regimen with cyclosporin, azathioprine, and pred- nisolone was used. Prednisolone was given initially at $2 \mathrm{mg} / \mathrm{kg} /$ day but the dose was reduced progressively from two weeks if there was no rejection and liver function was good. Figure 1 shows the mean prednisolone and cyclosporin doses. Azathioprine was given at a dose of 1.0$1.5 \mathrm{mg} / \mathrm{kg} /$ day and withdrawn at six months if no rejection was apparent. From January 1994 onward prednisolone was also stopped at three months in children with good graft function. Height was recorded at assessment and at all clinic visits. For the purpose of our study, height was recorded three monthly for the first 18 months, six monthly until three years, and yearly thereafter. At each visit, assessment included clinical examination, pubertal scoring, and anthropometry using a Harpenden stadiometer or Infantometer by one of three paediatricians. A patient was considered to have reached final height when at Tanner stage 5 and with height growth rate less than $0.5 \mathrm{~cm}$ in one year. Liver and renal function tests and a trough cyclosporin measurement were taken at each visit.

In statistical comparison of the growth data, the $\mathrm{z}$ score, standardised against the 1990 British growth reference data, ${ }^{18}$ was used. Severe growth retardation was defined as height below the 0.4 th centile. Midparental centile was calculated from parental heights and converted to a $\mathrm{z}$ score. Parental heights were measured where possible, but otherwise obtained by report from parents. Reported heights are less accurate than measured height, because subjects commonly overestimate their own and their spouses' heights. ${ }^{19}$ The effect of this bias is reduced by converting midparental height to a $\mathrm{z}$ score. Mean height $\mathrm{z}$ scores during follow up were calculated using within-subjects regression to ensure that means were representative of the entire group. Catch up growth was defined by improvement in the $\mathrm{zH}$ score. Prednisolone doses were expressed as $\mathrm{mg} / \mathrm{kg} /$ day for all children, including those on alternate day regimens. Tanner scores for pubertal staging were converted to $\mathrm{z}$ scores and a mean pubertal $\mathrm{z}$ score calculated by averaging breast and

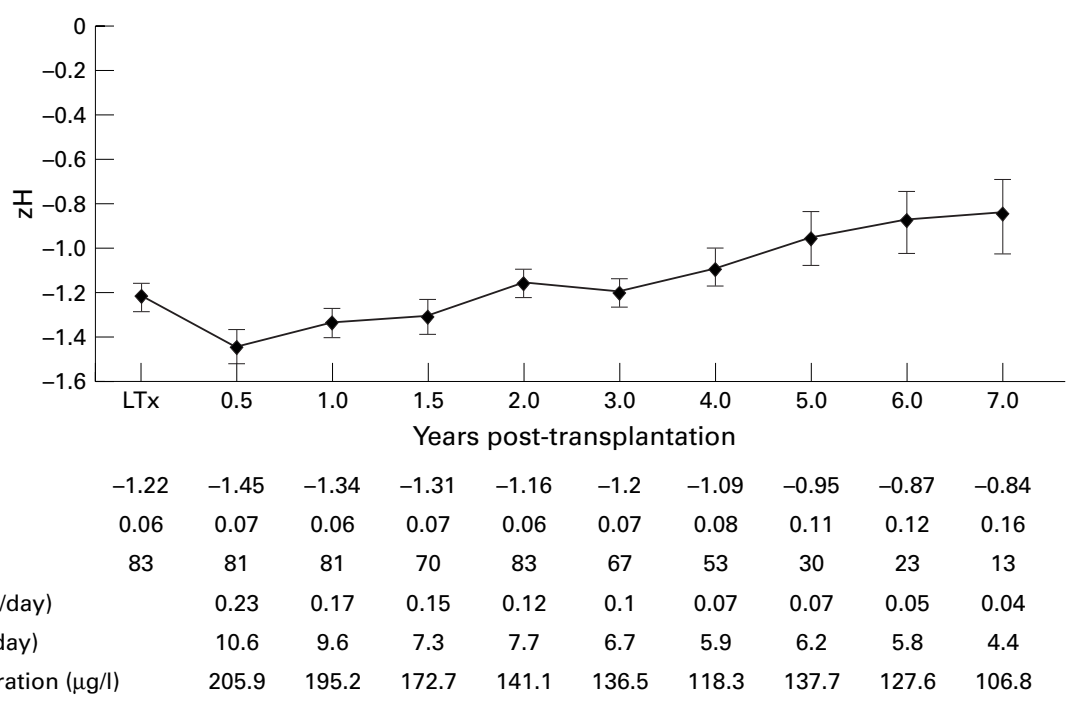

Figure 1 Height standard deviation scores $(z H)$, prednisolone, and cyclosporin during follow up. 
pubic hair scores for girls and genital, testicular, and pubic hair scores for boys. Comparison of groups was undertaken by unpaired $t$ tests and ANOVA; groups with less than four subjects were discarded for categorical analyses. Continuous variables were analysed by paired $t$ tests and multiple regression analysis. ${ }^{20}$

\section{Results}

Table 1 gives clinical details of the patients' sex, age bands, and diagnoses. Figure 1 shows the mean height $\mathrm{z}$ scores at liver transplantation and during follow up. The height of patients at transplantation was normally distributed. $\mathrm{zH}$ at transplantation was significantly below that of the general population $(\mathrm{p}<0.0001)$. Sixteen patients were severely growth retarded, but 20 had a positive $\mathrm{zH}$ with a height over the 50th centile. The severely growth retarded group was not significantly different from the remainder of the patients with respect to diagnosis, age, or liver function at transplantation.

Growth retardation was seen in the first six months after liver transplantation (fig 1); $\mathrm{zH}$ fell significantly by $0.22(\mathrm{p}<0.006)$ in the six months after transplantation. Significant catch up growth then occurred and was maximal from six months to two years $(p<0.01)$. In some patients, catch up growth continued until seven years, although the improvement in mean $\mathrm{zH}$ was significant only until five years after liver transplantation. $\mathrm{zH}$ at transplantation predicted $64 \%$ of the variance in $\mathrm{zH}$ at two years $(\mathrm{F}=121 ; \mathrm{p}<0.0001)$ and $53 \%$ of $\mathrm{zH}$ at five years $(\mathrm{F}=30.4 ; \mathrm{p}<0.0001)$. Of the patients who were severely growth retarded at liver transplantation, half remained so at four years (eight patients comprising $14 \%$ of the group at four years; diagnoses: five biliary atresia, one antitrypsin deficiency, one oxalosis, one tyrosinaemia; mean (SE) age at transplantation, 6.5 (1.7) years). Severe growth retardation at four years was not associated with an increase in post-transplant complications. There was no significant difference in $\mathrm{zH}$ during follow up for those undergoing transplantation before or after 1 January 1990, indicating that temporal changes in management were not responsible for the improvement in $\mathrm{zH}$.

Parental heights were available for 66 patients. Midparental height was normally distributed and the mean (SD) midparental $\mathrm{z}$ score was -0.17 (0.81), which was not significantly different from the general population. At liver transplantation, eight children were severely growth retarded when adjusted for their midparental centile (below 0.4 th centile for their midparental $\mathrm{z}$ score) and $28 \%$ remained so at four years after transplantation.

Final height was reached in 14 patients (six boys, eight girls; five with biliary atresia, four with antitrypsin deficiency, two with cystic fibrosis, and one each with chronic hepatitis, oxalosis, and familial hypercholesterolaemia; mean (SE) age at measurement, $17.5(0.3)$ years). Mean (SD) final $\mathrm{zH}$ was $-0.55(0.29)$, which was achieved at a mean (SE) of $4.6(0.5)$ years after transplantation. Mean (SE) midparental centile for this group was $0.11(0.25)$. The mean (SE) final $\mathrm{zH}$ in this group was not significantly better than the mean (SE) $\mathrm{zH}$ at transplantation $(-0.63(0.34))$. The mean (SE) age at transplantation in this group was 12.6 $(0.4)$ years, which was significantly older than that for the remainder of the children (5.1 (0.4) years; $F=53$; $<<0.0001$ ).

Diagnosis was not significantly associated with $\mathrm{zH}$ at liver transplantation, although those with cystic fibrosis and antitrypsin deficiency tended to have better pretransplant heights compared with those with metabolic conditions and biliary atresia. Those with biliary atresia (59 patients) showed significantly greater catchdown growth at six months after transplantation $(\mathrm{F}=8.3 ; \mathrm{p}<0.006)$, with a trend towards greater catch up at two years after transplantation. Those with metabolic conditions tended to show the least catch up, although this failed to reach significance. No significant differences were found between diagnoses in $\mathrm{zH}$ at six months after transplantation.

The mean (SD) age at transplantation was 6.1 (4.4) years for the entire group (range, $0.5-15.3$ years). Twenty four patients (23\%) underwent transplantation under the age of 2 years, $28(26.5 \%)$ between 2 and 5 years, 28 (26.5\%) between 5 and 10 years, and 25 (24\%) over 10 years. Age at transplantation was not associated with $\mathrm{zH}$ at that time. Those undergoing transplantation under 2 years had significantly greater growth catchdown at six months after transplantation $(\mathrm{F}=2.8$; $\mathrm{p}<0.05$ ), and a trend towards greater catch up from six months to two years after transplantation. However, six months posttransplantation, age at transplantation was not significantly associated with $\mathrm{zH}$ during follow up. Sex was not associated with height outcomes.

Pubertal data was available for 35 patients (17 boys, 18 girls; 15 with biliary atresia, five with antitrypsin deficiency, four with chronic hepatitis, four with cystic fibrosis, three with familial cirrhosis, three with oxalosis, and one with tyrosinaemia; mean (SE) age at transplantation, 10.6 (0.45) years). Mean pubertal $\mathrm{z}$ score fell from -1.0 at transplantation to -1.11 at six months, and subsequently improved to -0.91 at 12 months, -0.27 at three years, and -0.3 at five years, although these changes were not significant. Insufficient data were available for analysis of pubertal $\mathrm{z}$ scores after five years post-transplantation. Pubertal z score during follow up was not significantly predicted by sex, age at transplantation, or diagnosis, and was not associated with height growth during follow up. Data on the menarche were available in 18 patients. Mean (SE) age at menarche was 14.4 years (0.4), with a range of $12.1-17.50$ years, which was significantly delayed compared with the general population mean of 13.3 years $(p<0.02) .^{21}$

Twenty nine children $(27 \%)$ had a second transplant. In 15 of these children this was for acute perioperative events such as primary non-function of the liver and hepatic artery or portal vein thrombosis, and in 14 it was because of chronic rejection. The group who underwent retransplantation had a lower mean 
Table 2 Multiple regression models of height standard deviation score $(z H) 6$ months and 4 years after liver transplantation

\begin{tabular}{|c|c|c|c|c|}
\hline & Predictor variable & $\begin{array}{l}\text { Regression } \\
\text { coefficient }\end{array}$ & $t$ Value & $p$ Value \\
\hline \multirow{3}{*}{$\begin{array}{l}\text { Factors predicting } \mathrm{zH} 6 \text { months after transplantation } \\
\text { (regression model: } \mathrm{df}=63 ; \mathrm{F}=129.7 \text {; adjusted } \\
\mathrm{R}^{2}=87 \% ; \mathrm{p}<0.0001 \text { ) }\end{array}$} & $\mathrm{zH}$ at transplantation & 0.74 & 16.6 & $<0.0001$ \\
\hline & Bilirubin $(\mu \mathrm{mol} / \mathrm{l})$ & -0.001 & -2.6 & $<0.01$ \\
\hline & $\begin{array}{l}\text { Prednisolone dose at } 6 \text { months } \\
(\mathrm{mg} / \mathrm{kg} / \text { day })\end{array}$ & -1.58 & -2.3 & $<0.02$ \\
\hline \multirow{2}{*}{$\begin{array}{l}\text { Factors predicting } \mathrm{zH} 4 \text { years after transplantation } \\
\quad(\text { regression model: } \mathrm{df}=26 ; \mathrm{F}=26.8 \text {, adjusted } \\
\left.\mathrm{R}^{2}=67 \% ; \mathrm{p}<0.0001\right)\end{array}$} & $\mathrm{zH}$ at transplantation & 0.64 & 4.9 & $<0.0001$ \\
\hline & $\begin{array}{l}\text { Cumulative prednisolone dose } \\
\text { since transplantation (mg/kg) }\end{array}$ & -6.43 & -2.3 & $<0.02$ \\
\hline
\end{tabular}

$\mathrm{zH}$ throughout follow up, although the need for a second liver transplant was significantly associated with poorer height growth only at three years after transplantation (ANOVA: $\mathrm{F}=5.4$; $\mathrm{p}<0.02)$. Chronic rejection was not associated with height outcome.

Figure 1 shows prednisolone and cyclosporin doses. The mean prednisolone dose $/ \mathrm{kg} /$ day corrected for time after liver transplantation did not vary significantly over the 10 year span of our study. The prednisolone dose at six months after transplantation was a significant predictor of $\mathrm{zH}$ from six months to six years $(\mathrm{p}<0.01)$.

Multiple regression models were constructed for $\mathrm{zH}$ at six months and four years (table 2). Significant predictors for $\mathrm{zH}$ at six months were $\mathrm{zH}$ and bilirubin at transplantation, and prednisolone dose at six months. Factors that did not significantly predict $\mathrm{zH}$ at six months included age at transplantation, sex, diagnosis, cyclosporin dose and concentration, and the need for retransplantation. At four years, $\mathrm{zH}$ was predicted by $\mathrm{zH}$ at transplantation and the cumulative prednisolone dose at transplantation, but age, sex, diagnosis, liver function at transplantation, cyclosporin dose and concentration, and the need for retransplantation were not predictive.

\section{Discussion}

In our study we assessed growth and pubertal development in children up to seven years after liver transplantation. Although numbers were relatively small five years after transplantation, we believe this is the first report of long term growth and final height after liver transplantation in children. Our use of within-subsets regression to calculate mean $\mathrm{zH}$ during follow up indicates that results in the later years after transplantation were representative of the population undergoing transplantation. Unlike some other studies that have excluded those with abnormal liver function, the inclusion of all survivors provides a profile of posttransplant growth in children with and without postoperative complications, and with normal and abnormal liver function.

The children undergoing transplantation were heterogeneous. Although the mean height for the whole group at transplantation was on the 11 th centile, heights ranged from under the 0.4 th to the 99.6 th centiles. In contrast with previous reports that most children are severely growth retarded at the time of liver transplantation,,$^{3415}$ only $20 \%$ of our patients were severely growth retarded at that time. Indeed, when height was adjusted for midpar- ental centile only $15 \%$ were severely growth retarded. The bias likely to result from overreporting of parental height suggests that this discrepancy between $\mathrm{zH}$ at liver transplantation and a child's genetic potential might be overestimated. These differences from previous studies might reflect differences in the diagnostic profiles of the populations undergoing transplantation, differing policies on timing of transplantation and preoperative nutritional support, and failure to consider midparental centiles. The importance of pretransplant nutritional management and optimal timing of transplantation is emphasised by our finding that the height $\mathrm{z}$ score at transplantation was the most important predictor of later height outcome; indeed, children who were severely growth retarded at transplantation, in relation either to the midparental centile or the normal population, were over three times more likely to be severely growth retarded at four years.

Six to seven years after transplantation the mean height of the group stabilised at around four fifths of a standard deviation below that of the general population (that is, on the $22 \mathrm{nd}$ centile), having recovered only one third of their height deficit at transplantation. This is unsatisfactory compared with the normal population; however, the linear trend for improvement in $\mathrm{zH}$ visible from two to seven years after transplantation (significant until five years) suggests that further catch up will continue year upon year. This is particularly likely in those transplanted as infants, who have more opportunity to catch up.

The group who had reached final height showed no significant improvement from their pretransplantation $\mathrm{zH}$, with mean final height just over half a standard deviation less tall than the normal population and a similar amount less tall than their midparental mean. Although this corresponds with a mean final height on the 27 th centile, this result is again unsatisfactory compared with the general population. Reassuringly, these findings are not likely to be representative of all children undergoing liver transplantation, because the group at final height were mostly those transplanted in late childhood or early adolescence who had less opportunity for catch up growth. As noted above, the trend for continued catch up even at seven years after transplantation suggests that those transplanted in infancy are likely to reach final heights nearer to their genetic potential.

The pattern of growth retardation over the first six months, followed by catch up over the following 18 months, reflects the findings of other studies. ${ }^{4-6}$ As expected, high steroid doses 
and persisting liver dysfunction predicted growth failure at six months when controlled for other factors. Our finding that the growth suppressing effects of early high steroid doses remained apparent for up to five years was in contrast to previous studies in which it was reported that steroids affected growth for only two $^{7}$ or three ${ }^{6}$ years. These findings give extra weight to immunosuppression policy changes using lower doses of prednisolone and stopping this agent as early as possible. However, continued catch up growth up to seven years after transplantation suggests that the adverse effects of steroids on height are mostly recoverable once the dose is reduced. The confirmation that cyclosporin did not affect height outcome was reassuring. The association of the need for retransplantation with poorer height outcomes is not surprising, given the deleterious effects of chronic rejection and the return to high steroid doses after the second graft.

Age at transplantation did not predict later height outcome, although those transplanted under 2 years of age experienced the greatest growth delay and subsequent catch up, confirming the report by Holt et al. ${ }^{8}$ This finding is contrary to the recommendation by CodonerFranch et al that transplantation under 2 years of age should be avoided because of its association with worse height outcomes. ${ }^{6}$ As noted previously, the finding that catch up growth continued up to seven years after transplantation suggests that transplantation in those with the greatest potential number of years for catch up promises the best height outcomes. Confirmation that transplantation in infancy preserves height potential is important, in that transplantation in infancy is now the preferred management of many conditions requiring liver transplantation..$^{22}$

While those with biliary atresia showed the greatest initial growth delay and later catch up, diagnosis was not a significant predictor of later growth outcomes. Although numbers in each diagnostic group other than biliary atresia were small, this finding suggests that transplant related factors might outweigh diagnosis related factors in relation to growth. We did not confirm the suggestion that children with metabolic conditions might show the greatest catch up growth. ${ }^{6}$

Pubertal z scores followed a pattern similar to height scores, with a nadir at six to 12 months, followed by catch up up to five years after transplantation. The timing of menarche, was delayed by one year in comparison to recent British standards. Although pubertal z scores were not significantly associated with steroid dose or liver function, it is likely that the pattern of pubertal delay followed by catch up is related to the same factors as were identified for height growth. Reassuringly, pubertal $\mathrm{z}$ scores were essentially normal by five years after transplantation.

CONCLUSIONS

The mean height of the small group of patients who have reached final height after liver transplantation since 1985 was on the 27 th centile.

\section{Key messages}

- Average final height after liver transplantation was on the 27 th centile, although those undergoing transplantation as infants can achieve better final heights

- Height at transplantation is the most important predictor of later height outcome, emphasising the need for optimal transplant timing and preoperative nutritional management

- High steroid dose, poor liver function, and the need for a second transplant were associated with poor height outcome

- Transplantation in infancy was not associated with poorer height outcomes

- Normal pubertal progress was resumed three to five years after transplantation

Because catch up appears to continue until at least seven years after transplantation, those transplanted in early childhood are likely to achieve final heights nearer normal. We did not confirm previous findings that early transplantation might be associated with more severe growth failure. Indeed, there was a trend for younger patients to show greater catch up growth. Steroid dose, poor liver function, and the need for retransplantation each independently predicted worse height outcomes. Delay in pubertal development and menarche were common after liver transplantation, but appropriate pubertal progress was resumed after three to five years. Severe short stature after transplantation was mainly confined to those severely growth retarded at the time of transplantation, emphasising the need to preserve height potential by optimal pretransplant nutritional support and early transplantation. Further investigation of steroid growth suppression and of hepatic production of growth factors is needed, and a reassessment of height outcomes will be necessary when those undergoing transplant as infants reach final height.

1 Beath S, Pearmain G, Kelly D, McMaster P, Mayer A, Buckels J. Liver transplantation in babies and children with extrahepatic biliary atresia. F Pediatr Surg 1993;28:1044-7. 2 Chin SE, Shepherd RW, Cleghorn GJ, et al. Survival, growth and quality of life in children after orthotopic liver transplantation: a 5 year experience. $\mathcal{F}$ Paediatr Child Health 1991;27:380-5.

3 Urbach AH, Gartner JC, Malatack JJ, et al. Linear growth Urbach AH, Gartner JC, Malatack JJ, et al. Linear growth
following pediatric liver transplantation. Am $\mathcal{F}$ Dis Child following pediatric

4 Sarna S, Sipila I, Jalanko H, Laine J, Holmberg C. Factors affecting growth after pediatric liver transplantation. Transplant Proc 1994;26:161-4.

5 Moukarzel AA, Najm I, Vargas J, McDiarmid SV, Busuttil RW, Ament ME. Prediction of long-term linear growth following liver transplantation. Transplant Proc 1990;22:15589.

6 Codoner-Franch P, Bernard O, Alvarez F. Long-term ollow-up of growth in height after successful liver transplantation. F Pediatr 1994;124:368-73.

7 Rodeck B, Melter M, Hoyer PF, Ringe B, Brodehl J. Growth in long-term survivors after orthotopic liver transplantation in childhood. Transplant Proc 1994;26:165-6.

8 Holt R, Broide E, Buchanan C, et al. Orthotopic liver transplantation reverses the adverse nutritional changes of endstage liver disease in children. Am f Clin Nutr 1997;65:53442 .

9 Becht MB, Pedersen SH, Ryckman FC, Balistreri WF. Growth and nutritional management of pediatric patients after orthotopic liver transplantation. Gastroenterol Clin North Am 1993;22:367-80. 
10 Hokken-Koelega AC, van Zaal MA, van Bergen W, et al. Final height and its predictive factors after renal transplanFinal height and its predictive factors after renal
tation in childhood. Pediatr Res 1994;36:323-8.

11 Sarna S, Laine J, Sipila I, Koistinen R, Holmberg C. Differences in linear growth and cortisol production between liver and renal transplant recipients on similar immunosuppression. Transplantation 1995;60:656-61

12 Superina R, Acal L, Bilik R, Zaki A. Growth in children after liver transplantation on cyclosporine alone or in combination with low-dose azathioprine. Transplant Proc 1993;25: 2580 .

13 Tejani A, Fine R, Alexander S, Harmon W, Stablein D. Factors predictive of sustained growth in children after renal transplantation. The North American pediatric renal transplant cooperative study. F Pediatr 1993;122:397-402.

14 Cardona J, Houssin D, Gauthier F, et al. Liver transplantation in children with Alagille syndrome - a study of twelve cases. Transplantation 1995;60:339-42.

15 Laine J, Holmberg C, Sipila I, et al. Growth and renal function after liver transplantation in children. Transplant Proc 1992;24:398-400.
16 Giustina A, Girelli A, Alberti A, et al. Effects of pyridostigmine on spontaneous and GHRH-stimulated GH secretion in children on daily glucocorticoids after liver transplant. Clin Endocrinol 1991;35:491-8.

17 Holt R, Jones J, Stone N, Baker A, Miell J. Sequential changes in insulin-like growth factor-I (IGF-I) and IGF binding proteins in children with end-stage liver disease before and after successful orthotopic liver transplantation. f Clin Endocrinol Metab 1996;81:160-8.

18 United Kingdom cross-sectional reference data: 1995/1. London: Child Growth Foundation, 1995.

19 LeJarraga H, Laspuir M, Adamo P. Validity of reported parental height in outpatient growth clinics in Buenos Aires city. Ann Hum Biol 1995;22:163-6.

20 Aitken LS, West SG. Multiple regression: testing and interpreting interactions. London: Sage, 1991.

21 Eveleth P, Tanner J. In: Worldwide variation in human growth. Cambridge: Cambridge University Press, 1990:164.

22 Beath SV, Brook GD, Kelly DA, et al. Successful liver transplantation in babies under 1 year. BMF 1993;307:825-8.

\section{Intramuscular RSV antibody}

In the USA about half of all infants are infected with respiratory syncytial virus (RSV) during their 1st year of life and almost all are infected by the age of 3 years. The American Academy of Pediatrics has recommended that monthly intravenous injections of RSV immune globulin during the RSV season should be considered for infants with bronchopulmonary dysplasia who are receiving oxygen treatment or have done so in the previous six months and possibly for all infants born at or before 32 weeks' gestation. Because of the obvious limitations imposed by monthly intravenous injections, a humanised monoclonal antibody to the fusion protein of RSV (MEDI-493) that can be given intramuscularly has been studied in a multicentre trial in the USA, Panama, and Costa Rica (Xavier Saez-Llorens and colleagues. Pediatric Infectious Disease fournal 1998;17:787-91).

The study included 65 children, 24 with bronchopulmonary dysplasia aged up to 24 months and 41 aged up to 6 months without bronchopulmonary dysplasia but born at or before 35 weeks' gestation. They were given from one to five intramuscular injections of MEDI-493 at monthly intervals at dosages of 5,10 , or $15 \mathrm{mg} / \mathrm{kg}$. The $15 \mathrm{mg} / \mathrm{kg}$ dose produced mean trough serum concentrations of MEDI-493 of around $70 \mu \mathrm{g} / \mathrm{ml}$ (target $>40 \mu \mathrm{g} / \mathrm{ml}$ ). Two children receiving the $5 \mathrm{mg} / \mathrm{kg}$ dosage - but none on the higher dosages - were admitted to hospital with RSV infection. Three children had possible reactions, one with diarrhoea, fever, and increased respiratory symptoms, and two with mild, transient local erythema at the injection site. Ten children developed low litre antibodies to MEDI-493 that did not seem to be clinically important. MEDI-493 is much more potent than the RSV immunoglobulin preparation and appeared to be safe and effective at the $15 \mathrm{mg} / \mathrm{kg}$ dosage. These researchers conclude that it has several potential advantages over RSV immunoglobulin.

ARCHIVIST

1 American Academy of Pediatrics, Committee on Infectious Diseases Committee on Fetus and Newborn. Respiratory syncytial virus immune globulin intravenous: indications for use. Pediatrics 1997;99:645-50. 